\title{
7 Im Vorhof der indirekten Kommunikation: Clément Marot und die Entstehung einer Dichtung der ,causerie facile‘ als fingierte mündliche Konversation
}

\subsection{Gesellschaftliche und ideengeschichtliche Bedingungen der Kommunikation im 16. Jahrhundert}

Den gängigen historiographischen Untersuchungen zufolge liegen die ersten wichtigen Entwicklungen des neuzeitlichen absolutistischen Machtstaats im 16. Jahrhundert. Die europäischen Herrscher leiten seit dem Mittelalter ihre Macht von Gottes Gnaden ab, waren jedoch an Hoheitsfunktionen der Stände im feudalen System gebunden. Im entstehenden Absolutismus der modernen europäischen Staatensysteme gehen diese Hoheitsfunktionen nach und nach auf den Herrscher über. Die französischen Juristen hatten seit dem 13. Jahrhundert dieser Entwicklung den Boden bereitet und seit der Regentschaft von Ludwig dem Heiligen die Vorstellung verbreitet, dass der König ,souverain par-dessus tous“ sei. Mit dem Renaissancekönig François Ier wird diese Vorstellung maßgeblich vorangetrieben: Franz führt nicht nur Reformen im Finanz- und Verwaltungswesen durch, die der Stärkung der Macht der Krone dienen. Er veranlasst vor allem mit dem Artikel 111 des Edikts von Villiers-Cottérêt 1539 eine Sprachreform, die das Französische als alleinige Verwaltungssprache auf dem Territorium Frankreichs etabliert.

Begleitet werden diese Reformen von zahlreichen Diskussionen unterschiedlicher Staatstheoretiker. Während Claude de Seyssel in seinem Hauptwerk La Grande Monarchie de France (1519) die Kirche, die Gerichtshöfe (= ,les parlements') und den Verwaltungsapparat als Kontrollinstanzen der Monarchie beschreibt, die diese vor dem Fall in die Tyrannei bewahren, befürworten Guillaume Budé und Jean Bodin die absolutistische Zentralherrschaft. In seiner Institution du Prince von 1547 (geschr. 1519) erklärt Budé unter Hinweis auf das Gottesgnadentum der Monarchie, dass der König nicht den Gesetzen unterworfen ist (,de legibus solutus est'). Und im zweiten Buch seiner Six Livres de la République von 1576, die während der Religionskriege entstanden und gegen Machiavellis skrupellose Konzeption der Fürstenherrschaft im Principe (1513) auf der einen Seite sowie gegen die liberalen Staatskonzepte der protestantischen Monarchomachen auf der anderen Seite gerichtet sind, plädiert Bodin für eine absolute Monarchie, in der der Herrscher allein die Naturgesetze, die natürliche Freiheit und das Recht auf Eigentum, garantieren müsse. 
In diese Debatte schaltet sich auch der Dichter Clément Marot ein. Er tut dies in einer Form der Konversation mit dem Herrscher, die es erlaubt, eine grundlegende Kritik an dessen Herrschaft anzubringen. Marot macht die mündliche Konversation mit ihren Formen des indirekten Sprechens zum Maßstab seiner Gedichte und literarischen Episteln. Über seinen Plauderton, von der Literaturgeschichte als ,causerie facile' gehandelt und auch unter der an seinen Namen angelehnten Bezeichnung ,poésie marotique، (,scherzhafte Dichtung') bekannt, praktiziert er eine leichte, scherzhafte Art des Sprechens (,élégant badinage‘), mit der er sich in seinen Versepisteln häufig direkt an den König Franz wendet. Marots Dichtung steht im Kontext der höfischen Kommunikation und damit am Beginn des indirekten Sprechens, das sich dann im Laufe der weiteren zentralstaatlichen Entwicklung als Disposition und dominanter Habitus in Frankreich entwickelt. Seine Episteln und Epigramme ahmen den mündlichen Redestil nach und fügen seine Literatur auf diese Weise in die höfische Kommunikation ein. Dass die aus der mündlichen Konversation hervorgehenden indirekten Formen des Sprechens zu Beginn des 16. Jahrhunderts nicht nur bei Marot in den Rang einer Dichtung erhoben werden, verdankt sich bestimmten historischen und persönlichen Umständen.

Im 16. Jahrhundert liegen noch völlig andere soziale Bedingungen vor, als im darauffolgenden Jahrhundert, in dem sich neben der Hofgesellschaft die städtischen Salons entwickeln und zum Hof in ein Spannungsverhältnis treten. Erst im 17. Jahrhundert führen die Zentralisierungsanstrengungen Richelieus zu einer Konzentration der Macht auf den absoluten Herrscher Louis XIV, was die indirekte Form der Äußerung allein aus Gründen der Selbstbewahrung begünstigt. Die Salons, in denen vielfach Gleichgesinnte und Freunde aufeinander treffen, erlauben einen offeneren Umgangsstil unter den Beteiligten. Anfangs, in der Zeit der Frondeaufstände der Hohen Aristokratie gegen die Zentralisierungsbestrebungen, stehen die Salons sogar im Widerstand gegen den Hof. Auch hier ist allerdings - wie die bereits diskutierten zahlreichen Beispiele zeigen - die indirekte Redeweise an der Tagesordnung, da sich auch die Mitglieder der Salons bei aller freundschaftlichen Verbindung untereinander vor Verrat gegenüber der Zentralgewalt schützen müssen und da auch in den Salons vertikale Beziehungen einzelner Teilnehmer zueinander existieren. Unter den Bedingungen der eher offenen Begegnung im Salon kann die indirekte Redeweise jedoch Züge einer spielerisch-ästhetischen ,exception culturelle‘ gewinnen. Im Lauf des Jahrhunderts, nachdem die Salons diese politische Bedeutung durch die immer stärkere Homogenisierung der Kultur verlieren, wird der Hof von Versailles nicht nur Sitz des Staates sondern zugleich Zentrum des mondänen Lebens und der Kultur. Die Umgangsformen der Salons, die ,bienséances‘, die aus ihnen resultierenden Formen der ,politesse ${ }^{\text {‘ }}$ und ,civilité‘ werden auch die Umgangsformen am Hof: Es liegt eine „conversion d'une 
société de salon en société de cour"1 vor. Dieses Zusammenspiel von Hof und Salons war im 16. Jahrhundert nicht gegeben, zumal der Hof keinen festen Sitz hatte und die Regentschaft des Königs François Ier vom Reisekönigtum geprägt war.

Gleichwohl bildet sich in der an den König gerichteten Dichtung Clément Marots eine indirekte Sprechweise heraus, die ihre Ursachen zunächst einmal im Verhältnis von König und Dichter hat. Clément Marot hatte seit seiner Kindheit enge Verbindungen zu dem nur zwei Jahre älteren François: Sein Vater, der Autor Jean Marot, war Kammerdiener des französischen Königs und Vorgängers von François, Louis XII Clément selbst hatte in seiner Jugend eine Stelle bei der Chancellerie und war auf diese Weise mit dem Hofleben in ständigem Kontakt. 1519 wurde er Kammerdiener und Sekretär von Maguérite de Navarre, bzw. Marguérite d’Angoulême, der Schwester des Königs. 1526 erbte er das Amt seines Vaters und trat seinerseits als Kammerdiener in die Dienste des Königs, dem er über große Strecken seiner Kindheit und Jugend verbunden war. Dies erklärt, warum François Ier bei allen Verfolgungen des Dichters vor allem seitens der damals von den Theologen beherrschten Sorbonne als der obersten Zensurbehörde seine schützende Hand über ihn gehalten hat. Clément Marot hat mit seinen zahlreichen Versepisteln an François Ier ein bemerkenswertes Kunststück vollbracht: Die Episteln sind in der Regel Bittbriefe, in denen der Dichter vom König eine finanzielle Unterstützung erbittet. Auf eine indirekte und höchst amüsante Weise, die sich von den spielerisch-ästhetischen Sprechweisen der Hofgesellschaft inspirieren lässt, üben sie jedoch zugleich Kritik an der Politik des Königs und an den gesellschaftlichen Zuständen. Es ist dieser spielerisch-leichte Ton der Dichtung Marots, der laut Alain Génetiot der Grund dafür ist, dass der König den Dichter letzten Endes immer wieder unterstützt hat:

Marot s'est ainsi rendu célèbre par son art de la sollicitation spirituelle par où le valet de chambre de François Ier, fort de sa proximité avec le roi, demande et obtient non pas par la supplication, mais en enveloppant sa requête dans la bonne humeur qui dispose favorablement le roi à y accéder. ${ }^{2}$

Der spielerisch-leichte Ton der Marotschen ,causerie facile‘ begründet eine Richtung der französischen Literatur, die als ,littérature conversante‘ von der Litera-

1 Vgl. dazu Sophie Rollin, „De la société de salon à la société de cour: l'ambivalence du processus de civilisation“, in: FLS. Civilisation in French and Francophone Literature Bd. 23/2006, S. 131-145, hier: S. 143. Vgl. auch S. 132.

2 Alain Génetiot, „,L'élégant badinage“: Marot, Voiture et La Fontaine“, Le Fablier. Revue annuelle des amis de Jean de La Fontaine Bd. 27/2016, S. 39-46, hier: S. 45. 
turgeschichtsschreibung beschrieben wird und mit immer neuen Beispielen bis heute virulent ist.

Marot schreibt - dies ist eine weitere historische Spezifik seiner Epoche - aus der Haltung eines seit 1520 sich verbreitenden Evangelismus, der später in den Protestantismus mündet. In dieser Haltung ist er - dies lassen zahlreiche seiner Dichtungen erkennen - von Maguérite de Navarre beeinflusst und bestärkt worden. Sie protegiert neben Marot zahlreiche Intellektuelle und Schriftsteller, die den neuen Glaubensrichtungen positiv gegenüberstehen, darunter den Bibelübersetzer Jacques Lefèvre d'Étaples und die Reformatoren Jean Calvin und Martin Luther. Nach der berühmten Affaire des Placards von 1534, dem Anschlag protestantischer Thesen u. a. im Schloss des Königs in Amboise, ist François Ier gezwungen, sich von seiner Schwester zu distanzieren, da er als Herrscher über ein katholisches Land genötigt ist, die neuen Glaubensrichtungen zu bekämpfen. Marot ist seinerseits als Anhänger des Evangelismus gemäß dem Credo der neuen Glaubensrichtung einer grundlegenden Aufrichtigkeit verpflichtet. Evangelisten wie die späteren Protestanten vertreten die Idee der persönlichen Freiheit vor allem in Glaubensfragen. Neben dem Prinzip der ,sola fide“ ist für sie angesichts der Verfolgungen - dies zeigt $u$.a. die Auswanderung in die ,Neue Welt ${ }^{6}$ - auch der Gedanke der politischen Freiheit von besonderer Bedeutung. Zudem sehen sie sich auch in puncto wissenschaftlich-theologischer Forschung der Wahrheit verpflichtet, zweifeln sie doch an der Autorität der Kirche, die die Erforschung der biblischen Quellen zu verhindern sucht. All dies verbietet es Marot im Grunde, in seinen Dichtungen die Verstellung und das indirekte Sprechen als literarische Verfahren zu praktizieren.

Dem stehen jedoch die Erfahrungen durch die Bevormundung seitens katholisch-theologischer Autoritäten entgegen, die den Dichter mehrfach verhaften lassen bzw. ihn zur Flucht ins Ausland (Ferrara und Genf) zwingen. Und ein ganz besonderes Problem ist es für Marot, sich einem Herrscher zu beugen, der auf der einen Seite dabei ist, die theologischen Autoritäten im Zuge der Zentralisierung des Staatswesens seiner eigenen Kontrolle zu unterwerfen, um sich als absolute Autorität zu etablieren. Auf der anderen Seite ist dieser Herrscher, den Marot bestens kennt, wie er selbst Dichter und betätigt sich als Mäzen der Künste. Aus dieser Gemengelage heraus, die ein Musterbeispiel für die „Konfessionelle Ambiguität“ ist und geradezu die „Uneindeutigkeit und Verstellung als religiöse Praxis in der Frühen Neuzeit“"3 einfordert, entsteht Marots ,causerie facile‘. Sie nimmt sich die indirekte Form der Äußerung aus der Konversation zum Vorbild der Dichtung und

3 So der Titel und Untertitel einer Tagung des Excellenzclusters Religion und Politik 2010 an der Universität Münster (Konfessionelle Ambiguität. Uneindeutigkeit und Verstellung als religiöse 
bekräftigt auf diese Weise die Disposition, die die mündliche Konversation bei Hof und in den späteren Salons dominiert und sich ab dem 17. Jahrhundert zu einem allgemeinen kulturellen Habitus mit einer ,longue durée‘ entwickelt. Nach Génetiot hat der „badinage enjoué“ bei Marot nicht nur eine Unterhaltungsfunktion (,une fonction tout gratuite de divertissement“); er stammt aus der mündlichen Kommunikation („La conversation orale“), gewinnt jedoch im Zuge seiner Entwicklung zu einem schriftlichen Stil (,un style véritablement écrit“) maieutische Qualitäten und eine heuristische Funktion (,une fonction heuristique par sa vertu maïeutique“4).

Nach einhelliger Meinung der Dichter der ersten Hälfte des 16. Jahrhunderts, dem Jahrhundert der Hochblüte der französischen Renaissance, gilt Clément Marot als Dichterfürst seiner Zeit, als „Prince des Poetes Françoys“(Victor Brodeau ${ }^{5}$ ). Marot ist Übersetzer Vergilscher Eklogen sowie einer Reihe von Psalmen, die 1562 als älteste volkssprachliche Übersetzungen in den reformierten Psalter aufgenommen werden. Er ist Herausgeber des spätmittelalterlichen Roman de la Rose. Vor allem betätigt er sich jedoch als Dichter von ,rondeaux', ,complaintes‘, Eklogen, Balladen und insbesondere Epigrammen und Versepisteln.

Der Kanonisierungsprozess Marots durch die Literaturgeschichtsschreibung erfolgt, wie Wolfgang Preisendanz vor einiger Zeit gezeigt hat ${ }^{6}$, bis zum Ende der achtziger Jahre wie bei kaum einem Autor der französischen Literatur hauptsächlich unter einem Gesichtspunkt: Marot gilt seit Boileaus Diktum aus dem

Praxis in der Frühen Neuzeit, hrsg. von Andreas Nicolaus Pietsch und Barbara Stollberg-Rillinger [Schriften des Vereines für Reformationsgeschichte. 214], Gütersloh, Gütersloher Verlagshaus, 2013).

4 ,,L'élégant badinage““, S. 45.

5 Vgl. dazu den Band Hecatomphile. De vulgarie [sic] Italien tourné en langaige Françoys. Les fleurs de Poesie Françoyse, Paris, Galliot du Pré, 1534. Kommentiert in: Clément Marot, Euvres poétiques complètes, 2 Bde, hrsg. von Gérard Defaux (Classiques Garnier), Paris, Garnier, 1993, Bd. 2, S. 1319-1322. Zu den folgenden Textanalysen vgl. auch Vf., „Das Konzept politischer Herrschaft in der Dichtung Clément Marots“, in: Marc Föcking/Bernhard Huss (Hrsg.), Varietas und Ordo. Zur Dialektik von Vielfalt und Einheit in Renaissance und Barock (Text und Kontext), Stuttgart, Steiner, 2002, S. S. 153-166, sowie „Die Kunst des Streitens. Clément Marots Bittbriefe an François $\mathrm{I}^{\mathrm{er}}$ “, in: Marc Laureys/Roswitha Simons (Hrsg.), Die Kunst des Streitens. Inszenierung, Formen und Funktionen des öffentlichen Streits in historischer Perspektive (Super alta perennis. Studien zur Wirkung der Klassischen Antike. 10), Göttingen, Bonn University Press bei V\&R unipress, 2010, S. 245-255.

6 „Gattungshorizont des Epigramms und ,style marotique““, in: Wolf-Dieter Stempel/Karlheinz Stierle (Hrsg.), Die Pluralität der Welten. Aspekte der Renaissance in der Romania (Romanistisches Kolloquium. 4), München 1987, S. 279-300, bes. S. 279 f. Preisendanz bezieht sich auf Yves Girauds „Les jugements de la critique“ in der von diesem besorgten Ausgabe: Clément Marot, Euvres poétiques (GF. Texte intégral. 259), Paris, Garnier-Flammarion, 1973, S. 486-491. 
Art poétique als Dichter des Elegant-Scherzhaften („élégant badinage“7). Laut Sainte-Beuve im 19. und nach ihm Leo Spitzer im 20. Jahrhundert kommt ihm das Verdienst zu, die Plauderei („la causerie facile“8) in die Literatur eingeführt zu haben. Natürlichkeit, Charme, Grazie, Zwanglosigkeit und Naivität gelten als Charakteristika des nach dem Dichter benannten ,style marotique'9.

Nun stehen ,causerie facile" und ,badinage" in der Phase der aristokratischhöfischen Gesellschaft zur Zeit Ludwigs des XIV. im Zeichen einer Ästhetik der ,diversitê‘, die sich den normativen Ansprüchen der französischen Klassik widersetzt. Der Art poétique eines Boileau zielt auf die Konzentration und auf die Unterordnung der Details unter die Einheit des Ganzen innerhalb eines literarischen Werks. Demgegenüber spiegeln sich in der Regelfreiheit des „Unernst-Unverbindlichen" der ,causerie facile، - so Fritz Nies in seiner Arbeit über die Briefe der Mme de Sévigné ${ }^{10}$ - die Auffassungen einer Aristokratie, die sich den ästhetischen Ordnungsbestrebungen der Klassik und darüber hinaus politisch den Unterwerfungsmechanismen des Absolutismus entzieht ${ }^{11}$.

In der Epoche der Frühen Neuzeit gibt es für die Schriftsteller anders als im 17. Jahrhundert noch kein staatlich organisiertes Mäzenatentum, wie es Richelieu mit Unterstützung des Finanzministers Colbert organisiert hatte. Die Epoche der Frühen Neuzeit ist die Hochzeit der Widmungsbriefe und der Bittbriefe, der ,épîtres dédicatoires' und der ,lettres de requêtes', mit denen sich die Schriftsteller der Gunst freigebiger Gönner zu versichern trachten. Die Wiederbelebung der schon in der Antike gepflegten Sitte, Schriften einem Gönner zuzueignen oder die Großen in Bittschreiben um Unterstützung anzugehen, hat bis zur Zeit der Regentschaft Ludwigs des XIV. Konjunktur. Eingedämmt durch das flächendecken-

\footnotetext{
7 Art poétique I, V. 96.

8 Vgl. dazu Leo Spitzer, „Clément Marot. Eclogue au Roy, soubs les noms de Pan et robin (1539)“, in: Leo Spitzer, Interpretationen zur französischen Lyrik, hrsg. von Helga Jauß-Meyer und Peter Schunck, Heidelberg, Selbstverlag des Romanischen Seminars der Universität Heidelberg, 1961, S. 24-43, hier: S. 42.

9 Vgl. Preisendanz, „Gattungshorizont“, S. 279 f. Zu den Ursprüngen der Bezeichnung ,marotique bei Furetière im 17. Jahrhundert vgl. Isabelle Landy-Houillon, „Autour d'un marqeur stylistique: le marotique“, in: Jean-Charles Montferran (Hrsg.), Le Génie de la langue française autour de Marot et La Fontaine. L'Adolescence clémentine, Les Amours de Psyché et de Cupidon (Feuillets), Fontenay-aux-Roses/Paris, ENS Éditions, 1997, S. 133-146, bes. S. 134.

10 Gattungspoetik und Publikumsstruktur. Zur Geschichte der Sévignébriefe (Theorie und Geschichte der Literatur und der Schönen Künste. 21), München, Wilhelm Fink, 1972, bes. S. 80. Vgl. auch Jean Rousset, La littérature de l'âge baroque en France. Circé et le Paon, Paris, José Corti ${ }^{5} 1965$ (1954), S. $197 \mathrm{f}$.

11 Vgl. auch unten, das Kap. 9 über Jean de La Fontaine.
} 
de System staatlicher Pensionen und Zahlungen, das Richelieu dann als Steuerungsinstrument des aufkommenden absolutistischen Staates aufbaut, verlieren die Buchwidmung und der Bittbrief nach und nach ihre Bedeutung, bevor die Aufklärung darin ein Zeichen schriftstellerischer Unmündigkeit sieht.

In seiner grundlegenden Monographie zum Widmungsbrief in der französischen Literatur behandelt Wolfgang Leiner nahezu alle Formen, Formeln, Anlässe und Funktionen der Gattung in der Zeit zwischen 1580 und 1715². Leiner geht jedoch einer Frage überhaupt nicht nach: Kann man einen Widmungsbrief dazu nutzen, mit dem Gönner über grundlegende politische, religiöse und weltanschauliche Probleme zu streiten und sich gleichzeitig seiner Gunst versichern? Um wie viel mehr gilt dies für die Gattung des literarischen Bittbriefes. Wie kann ich den Mäzen, an den ich mich wende, mit Positionen behelligen, die seinen eigenen zuwiderlaufen und dennoch Zuwendungen von ihm erhalten? Und das, wo der literarische Brief aufgrund der spezifischen Kommunikationssituation bei Hof sich zudem noch an ein größeres Publikum wendet und damit einen ausgesprochen performativen Charakter hat. Die Verzweiflung der Autoren angesichts solcher nahezu unüberbrückbaren Widersprüche entlädt sich immer wieder. Ein berühmter Fall ist Pietro Aretinos Widmung seiner Hetärengespräche, die 1548 erschienenen Ragionamenti, an seinen Affen Mona. Der Affe sehe aus, so heißt es, wie die Mäzene der Zeit. Wie Mona würden diese ,Großkotze' nicht nur die Bücher zerfetzen, die ihnen gewidmet sind, sondern sie putzten sich - so Aretino „mit den Blättern den - fast hätte ich das Wort ausgesprochen [...]”13. Nun hat Aretino offenbar nicht die Absicht gehabt, durch ein solches Widmungsschreiben eine Zuwendung von wem auch immer zu erhalten. Das Kunststück mit dem Gönner zu streiten und nachweislich gleichwohl dafür immer wieder eine Zuwendung zu erlangen, hat Marot fertig gebracht. Dessen häufig als ,lettres de requête، angelegte Versepisteln an den französischen König François Ier spielen zudem bei der Auseinandersetzung zwischen Protestanten und Katholiken im öffentlichen Raum der ersten Hälfte des 16. Jahrhunderts eine erhebliche Rolle. Mit welchen persuasiven Strategien der indirekten Kommunikation Marot dabei zu Werke geht, lässt sich an einigen dieser Briefe zeigen.

12 Wolfgang Leiner, Der Widmungsbrief in der französischen Literatur (1580-1715), Heidelberg, Winter, 1965, S. 20-26.

13 Pietro Aretino, I Ragionamenti, hrsg.von Antonio Foschini (Ammiraglia), Milano, dall'Oglio, 1967, S. 192: „[...] i gran Maestri non pure squarciano le cose che se gli indirizzano, ma se ne forbiscono poco meno ch'io non te lo dissi [...]“ 


\subsection{Marots Testament seines Vaters Jean Marot und die Rolle des Hofdichters}

Eine der bekanntesten Versepisteln Clément Marots ist der frühe Brief aus dem Jahr 1527 anlässlich des Todes seines Vaters Jean Marot, der nicht nur als Dichter sondern auch als Historiograph Ludwigs XII. tätig war ${ }^{14}$. In dieser Epistel Au Roy an François Ier liefert Marot in Grundzügen sein Verständnis von der angestrebten Rolle als Hofdichter. Vordergründig ist diese Epistel des Dichters, wie zahlreiche andere auch, ein Bittbrief, eine ,lettre de requête'. Marot wendet sich mit dem gebotenen Respekt an den König, wobei der Brief gleichwohl im Plauderton mündlicher Konversation gehalten ist.

Non que par moy soit arrogance prinse, Non que ce soit par suieuse emprinse D'escrire au Roy: pour tout cela ma Plume D’ardant desir de voller ne s'allume.

5 Mon juste dueil (seulement) l'a contraincte De faire à vous (et non de vous) complaincte.

Il vous a pleu, Sire, de pleine grâce Bien commander, qu'on me mist en la place Du Pere mien, vostre serf humble mort:

10 Mais la Fortune, où luy plaist, rit, \& mord.

Mords, elle m'a, \& ne m'a voulu rire,

Ne mon nom faire en voz Papiers escrire.

L’Estat est faict, les Personnes rengées,

15 Le Parc est clos, et les Brebis logées

Toutes, fors moy le moindre du Trouppeau, Qui n'a Toyson, ne Laine sur la peau.

[...]

$\mathbf{2 0}$ Certes mon cas pendoyt à peu de chose, Et ne falloit, Sire, tant seulement, Qu'effacer Jan, \& escrire Clement.
Nicht, dass mich die Arroganz ergriffen hat, Nicht aus Neugier heraus

Dem König zu schreiben: Wegen all dem

Flammt meine Feder nicht auf, um sich aus brennendem Verlangen heraus zu erheben. Mein gerechter Schmerz (allein der) hat sie genötigt Euch (und nicht über euch) eine Beschwerde vorzutragen.

Es hat Euch gefallen Herr, wohl mit voller Gnade Anzuordnen, dass man mich an die Stelle Meines Vaters, Eures verstorbenen, bescheidenen Dieners setzt.

10 Aber das Schicksal lacht und beißt, wo es ihm gefällt.

Gebissen hat es mich und hat mir weder zulachen wollen,

Noch gewollt, dass mein Name in Eure Listen eingetragen wird.

Der Haushalt ist aufgestellt, die Personen sind eingeordnet,

15 Der Park ist geschlossen und die Schafe untergebracht,

Alle, außer mir, der geringste der Herde, Der weder Haare noch Wolle auf der Haut hat. [...]

20 Sicherlich hing mein Fall nur von Wenigem ab, Und es bedurfte, Herr, nur des Durchstreichens Von Jean und des Hinschreibens von Clément.

14 Zitierte Ausgabe Marot, Euvres poétiques complètes, Bd. 1, S. 327-330. 
Or en est Jan par son trespas hor mis,

Et puis Clement par son malheur obmis,

25 C'est bien malheur, ou trop grand oubliance:

Car quant à moy, j’aye ferme confiance, Que vostre dire est ung divin Oracle, Où nul vivant n'oseroit mettre obstacle.

Telle tousjours a esté la parolle

30 Des Roys, de qui le bruit aux Astres volle. Je quiers sans plus, Roy, de los eternel, Estre heritier du seul bien Paternel.

[...]

Si est il mort, ainsi qu’il demandoit:

40 Et me souvient, quand sa mort attendoit,

Qu'il me disoit, en me tenant la Dextre:

Filz, puis que Dieu t'a fait la grâce d'estre Vray Heritier de mon peu de sçavoir,

Quiers en le bien, qu'on m'en a faict avoir :

45 Tu congnois, comme user en est decent. C'est ung sçavoir tant pur, \& innocent, Qu'on n'en sçauroit à creature nuire. Par Preschemens, le Peuple on peult seduire: Par Marchander, tromper on le peult bien: 50 Par Plaiderie, on peult menger son bien :

Par Medecine, on peult l'homme tuer:

Mais ton bel Art ne peult telz coups ruer:

Ains en sçauras meilleur Ouvrage tistre: Tu en pourras dicter Lay, ou Epistre, 55 Et puis la faire à tes Amis tenir, Pour en l'Amour d'iceulx t'entretenir. Tu en pourras traduire les Volumes

Jadis escriptz par les divines Plumes Des vieulx Latins, dont tant est mention.
Nun ist Jean durch seinen Tod herausgestrichen worden

Und dann Clément durch sein Unglück ausgelassen worden.

25 Es ist wohl ein Unglück, oder zu große Vergesslichkeit:

Denn, was mich angeht, habe ich festes Vertrauen, Dass Eure Rede ein göttliches Orakel ist, Dem kein Lebender würde wagen, ein Hindernis entgegenzustellen.

Dergestalt war immer das Wort der Könige, 30 Deren Ruhm bis zu den Sternen fliegt. Ich ersuche allein, König von ewigem Ruhm, Das Erbe des einzigen väterlichen Gutes anzutreten.

[...]

Als er gestorben ist, hat er mich [folgendes] gefragt:

40 Und ich erinnere mich, als er seinen Tod erwartete,

Dass er zu mir, indem er meine rechte Hand hielt, sagte:

Sohn, da Gott Dir die Gnade erwiesen hat, Der wahre Erbe meines geringen Wissens zu sein,

Ersuche das Gut, dass man mir hat zuteil werden lassen:

45 Du weißt, wie sittsam der Umgang damit ist. Es ist ein so reines und unschuldiges Wissen, Dass man damit niemand schaden kann.

Mit Predigen kann man das Volk verführen, Mit Handeltreiben kann man es wohl täuschen: $\mathbf{5 0}$ Mit Prozessieren kann man sein Vermögen aufzehren:

Durch die Heilkunst kann man den Menschen töten:

Aber Deine schöne Kunst kann solche Schläge nicht schlagen:

Vielmehr kannst Du ein besseres Werk weben: Du kannst Vermächtnisse oder Briefe diktieren 55 Und sie dann Deinen Freunden unterbreiten, Um Dich in Freundesliebe mit ihnen zu verbinden. Du wirst Bände der alten Lateiner, um die man jetzt viel

Aufhebens macht, übersetzen können, Die einst mit Gottes Feder geschrieben worden sind. 
60 Apres tu peulx de ton invention Faire quelcque CFuvre [pour] jecter en lumiere :

Dedans lequel en la Fueille premiere Doibs invocquer le nom du tout puissant:

Puis descriras le bruit resplendissant 65 De quelcque Roy, ou Prince, dont le nom

Rendra ton Fuvre immortel de renom:

Qui te fera (peult estre) si bon heur, Que le proffit sera joinct à l'honneur. Donc pour ce faire, il fauldroit que tu prinses 70 Le droict chemin du service des Princes: Mesme du Roy, qui cherit, \& practique

Par son hault sens ce noble Art Poëtique. Va donc à luy, car ma fin est presente, Et de ton faict quelcque Euvre luy presente, $\mathbf{7 5}$ Le suppliant, que par sa grand doulceur,

De mon estat te fasse successeur.

[...]

Ainsi disoit le bon Vieillard mourant:

$\mathbf{8 0}$ Et aussi tost que vers vous fuz courant, Plus fut en vous Liberalité grande, Qu'en moy desir d`impetrer ma demande. Je l'impetray, mais des fruictz je ne herite.

Vray est aussi, que pas ne les merite, $\mathbf{8 5}$ Mais bien est vray, que j'ayd'iceulx besoin.

Or si le cueur, que j'ay de prendre soing

A vous servir, si ceste Charte escripte,

Ou du Deffunct quelcque faveur petite Ne vous esmeut (ô Sire) à me pourveoir,

90 A tout le moins vous y vueille esmouvoir Royal promesse, en qui toute asseurance

Doibt consister. Là gist mon esperance,

Laquelle plus au Deffunct ne peult estre,
60 Danach kannst Du aus eigener Findung Ein Werk schaffen und ans Licht bringen,

Auf dessen erster Seite

Du den Namen des Allmächtigen anrufen mußt:

Sodann wirst Du den strahlenden Ruhm

65 Irgendeines Königs, oder Fürsten, beschreiben, dessen

Name Deinem Werk unsterblichen Nachruhm verleihen wird:

Der Dir (vielleicht) so rechtzeitig zuteil wird, Dass sich Ertrag und Ehre verbinden. Um dies also zu tun, musst Du den direkten Weg 70 In die Dienste der Fürsten nehmen: Vor allem des Königs, der aufgrund seiner hohen Geistesart die edle Dichtkunst in Ehren hält und selbst praktiziert.

Geh also zu ihm, denn mein Ende ist gegenwärtig, und unterbreite ihm ein Werk Deines Schaffens, 75 Bitte ihn, daß er Dich aufgrund seiner großen Milde

Zum Nachfolger meines Etats macht.

[...]

So sprach der gute Alte im Sterben:

80 Und alsbald lief ich zu Euch,

Eure Freigebigkeit war größer als mein Wunsch, Das Ziel meiner Bitte zu erreichen.

Ich erreichte es, aber Früchte ernte ich daraus nicht.

Wahr ist auch, dass ich sie nicht verdiene.

$\mathbf{8 5}$ Aber es ist auch wahr, dass ich sie benötige.

Wenn nun das Herz, das darauf bedacht ist, sorgfältig

Euren Dienst zu versehen, wenn dieses

Schriftstück,

Oder irgendein kleiner Dienst des Verstorbenen

Euch nicht dazu bewegt (oh Herr), mich zu versorgen,

90 Möge Euch doch wenigstens

das königliche Versprechen bewegen, auf dass

ich mich ganz

Verlassen können muss. Darin liegt meine

Hoffnung,

Die dem Verstorbenen nicht mehr zuteil werden kann, 
Combien qu'il eust double bien, comme ung Prebstre

95 C'est assçavoir Spiritualité, Semblablement la Temporalité

Son Art estoit son bien Spirituel:

Et voz Biensfaictz estoient son Temporel.

Or m'a laissé son Spirituel bien:

100 Du Temporel jamais n'en auray rien,

S’il ne vous plaist le commander en sorte,

Qu'obeissance (à mon profit) en sorte. ${ }^{15}$
Obgleich er wie ein Priester ein doppeltes

Gut besaß:

95 Nämlich Geistigkeit

Sowie das Zeitliche.

Seine Kunst war sein geistiges Gut:

Und Eure Wohltaten waren sein zeitliches.

Nun hat er mir sein geistiges Gut

hinterlassen:

100 Vom zeitlichen werde ich niemals

etwas besitzen,

Wenn es Euch nicht gefällt, einen derartigen

Befehl zu geben,

Dass daraus Gehorsam (zu meinen Gunsten) erwächst.

Der König habe versprochen, so heißt es in V. 7-9, dass Clément den Platz seines verstorbenen Vaters als ,valet de chambre du Roi‘ einnehmen soll. Man habe jedoch leider vergessen, seinen Namen in die königlichen Bestallungslisten einzutragen (die Verse 12 und 20-22). Um François Ier an sein Versprechen zu erinnern (V. 90 f.), berichtet der Brief von einem Gespräch zwischen Clément und seinem Vater an dessen Totenbett, in dem dieser seinem Sohn sein Vermächtnis mit auf den Weg gibt (V. 40-79).

Der Brief ist zumindest äußerlich ganz vom Elegant-Scherzhaften, vom ,style marotique، geprägt. So heißt es ab V. 10, das Schicksal habe Clément bei der Aufstellung des königlichen Haushaltes gebissen und ihn als kleinstes Schäfchen ohne Wolle aus der Herde ausgesperrt. ${ }^{16}$ Der Biss des Schicksals wird dramatisch gleich mit dem Tod assoziiert, was spielerisch über das Wortspiel der homophonen Bezeichnungen „La Fortune mord“ und „,vostre serf humble mort“ aus V. $9 \mathrm{f}$. dem Adressaten nahe gelegt wird. Unter den ,élégant badinage‘ fällt auch die Äußerung der Verse 25-30, dass das Wort des Königs ein göttliches Orakel sei. Offenkundig, so der ironische Unterton der Stelle, waren die Worte des König allzu orakelhaft, haben die Beamten doch Clément nicht auf die Gehaltsliste gesetzt.

15 Clément Marot, Au Roy, aus: La suite de l'adolescence clémentine, in: Euvres poétiques complètes, Bd. 1, S. 327-330 (Nr. XXIV).

16 „Mais la Fortune, où luy plaist, rit, \& mord.

Mords, elle m'a, \& ne m'a voulu rire,

Ne mon nom faire en vos Papiers escrire.

L'estat est faict, les Personnes rengées,

Le Parc est clos, et les Brebis logées

Toutes, fors moy le moindre du Trouppeau,

Qui n’a Toyson, ne Laine sur peau.“ 
Die Worte der Könige, die bis zu den Sternen fliegen - so heißt es satirisierend seien stets derart orakelhaft gewesen:

C'est bien malheur, ou trop grand oubliance:

Car quant à moy, j’aye ferme confiance, Que vostre dire est ung divin Oracle, Où nul vivant n'oseroit mettre obstacle. Telle tousjours a esté la parolle

Des Roys, de qui le bruit aux Astres volle.

Voller Ironie ist dann später ab V. 64 die Empfehlung Jean Marots an seinen Sohn, er müsse als Dichter vom strahlenden Ruhm eines Herrschers berichten, um dessen Namen für den Nachruhm des eigenen Werkes zu nutzen:

Puis descriras le bruit resplendissant

De quelcque Roy, ou Prince, dont le nom

Rendra ton Euvre immortel de renom [...]

Jean hatte sich nämlich zu Lebzeiten um seine eigenen Werke überhaupt nicht gekümmert. Erst Clément begründet den Nachruhm seines Vaters durch die Herausgabe von dessen ,Euvre‘. Die Stelle ist überdies aus einem anderen Grund voller Ironie, war François doch kurz zuvor 1525 von seinem Gegenspieler, Kaiser Karl V., in Pavia gefangen genommen und nach Madrid verbracht worden. Das Erbe Jean Marots, so heißt es ab V. 95 in einer weiteren scherzhaften Pointe am Schluss der Epistel, sei geistiger und weltlich-materieller Natur ${ }^{17}$. Geerbt habe Clément vom Vater bislang nur den geistigen Anteil, während der König für die zeitlich-materiellen Wohltaten zuständig sei (V. 97 f.):

Son Art estoit son bien Spirituel:

Et voz Biensfaictz estoient son Temporel.

Or m’a laissé son Spirituel bien:

Du Temporel jamais n'en auray rien,

S’il ne vous plaist le commander en sorte,

Qu'obeissance (à mon profit) en sorte.

Gerade diese scherzhaft-ironisierenden Bemerkungen sind es jedoch, die qua ,integumentum' die Leitlinien einer stark politisch geprägten Poetik kennzeichnen. Die grundsätzliche Verankerung dieser Poetik Clément Marots in der reformatorisch-evangelischen Bewegung der Zeit ist der Literaturgeschichtsschreibung

17 „C'est assçavoir Spiritualité, Semblablement la Temporalité.“ 
trotz der eingangs erwähnten Aufklärungsbemühungen seit dem Ende achtziger Jahre $^{18}$ bislang nur für wenige Texte gelungen. Schaut man sich das literarische Vermächtnis, das Jean Marot seinem Sohn hinterlässt, genau an, so fällt alsbald auf, dass der Sohn dem Vater nur seine eigenen Vorstellungen in den Mund legt, mit denen er sich von der traditionellen Rolle des Hofdichters abgrenzt. Diese hatte sein Vater an den Höfen von Louis XII und François Ier geradezu mustergültig ausgefüllt.

In den Vorbemerkungen zu seinem bekanntesten Werk Le Voyage de Gênes, dem in Versen abgefassten Bericht von der kriegerischen Auseinandersetzung des Königs Ludwig mit den Genuesern im Jahr 1507, sieht Jean Marot seine hauptsächliche Aufgabe neben der Unterhaltung seines Herrn in der Behandlung staatstragender Sujets („matieres graves“19). Im Besonderen geht es ihm um die Verherrlichung des Sieges des christlichen Königs (,coucher par escript la magnamime victoire du roy treschretiens Loys XII $\left.{ }^{\mathrm{e}}{ }^{20}\right)$. Als ,croniqueur' und Hofhistoriograph glorifiziert er die Kriegstaten des Regenten, über die er dessen Namen im kollektiven Gedächtnis der Nachwelt zu verankern sucht. Ein Blick auf das angebliche Vermächtnis des Vaters an seinen Sohn in Cléments Epître au Roy zeigt jedoch, dass gerade dieser Aspekt völlig fehlt. Stattdessen heißt es in den eingängigen Versen 69 ff., Clément müsse vor allem in die Dienste des Königs treten, der die Dichtkunst praktiziert:

[...] il fauldroit que tu prinses

Le droict chemin du service des Princes:

Mesme du Roy, qui cherit, \& practique

Par son hault sens ce noble Art Poëtique.

18 Vgl. dazu vor allem die Arbeiten von Gérard Defaux, Marot, Rabelais, Montaigne. L'écriture comme présence (Etudes montaignistes. 2), Paris/Genève, Champion/Slatkine, 1987 sowie die Kommentare und die „Introduction“ von Defaux zu seiner Marot-Ausgabe (Euvres poétiques complètes, Bd. 1, S. XVII-CLXIX). Vgl. auch die grundlegenden Arbeiten von Paulette Leblanc, La Poésie religieuse de Clément Marot, Paris, Klincksieck 2019 ( $\left.{ }^{1} 1955\right)$, Claude-Albert Mayer, La Religion de Marot, Paris, Nizet, 1973 ( ${ }^{1}$ Genève 1969) sowie Michael A. Screech, Marot évangélique (Études de philologie et d'histoire. 4), Genève, Droz, 1967 und ders., Clément Marot. A Renaissance Poet Discovers the Gospel. Lutheranism, Fabrism and Calvinism in the Royal Courts of France and of Navarra and in the Ducal Court of Ferrara (Studies in Medieval and Reformation Thought. 54), Leiden/New York/Köln, Brill, 1994.

19 Jean Marot, Le Voyage de Gênes, hrsg. von Giovanna Trissolini (Textes littéraires français), Genève, Droz, 1977, S. 83.

20 Ebd. 
Die Verherrlichung von François Ier als Musenkönig ${ }^{21}$ steht nun im Zentrum der zahlreichen Traktate zur Prinzenerziehung sowie zur Organisation des Staates, in denen zwischen 1510 und 1520 eine Debatte über die Staatsführung geführt wird $^{22}$ und in denen sich die Anschauungsmuster der Epître au Roy in systematischer Form bis in die Formulierungen hinein wiederfinden. In dieser Debatte geht es auch ganz wesentlich um die Ergründung orakelhafter Worte, um Formen des indirekten Sprechens. Neben der grundsätzlichen Frage, ob der Herrscher absolute Macht besitzt oder den Gesetzen unterworfen ist - veranschaulicht in den Formeln ,princeps legibus solutus est' bzw. ,princeps legibus non solutus est ${ }^{\star}$ handeln die Traktate vor allem davon, welche Faktoren die Machtausübung des Fürsten beeinflussen. Während Thomas Morus in seiner Utopia von 1516 und de Seyssel in La Grand Monarchie de France stärker auf die Organisationsprinzipien und Kontrollmechanismen staatlicher Macht abheben, rücken Erasmus von Rotterdam in der Institutio principis christiani von 1516 sowie dann vor allem Budé in seiner Schrift De l'Institution du Prince ganz das ungebrochene Vertrauen auf die Bildung und die Vernunft des Herrschers in den Mittelpunkt, was angesichts der starken Betonung des Gottesgnadentums der Königsherrschaft bei Budé nicht weiter verwunderlich ist. Der Rechtsgelehrte, Altertumswissenschaftler und Gründungsvater des Collège des lecteurs royaux (1530), des heutigen Collège de France, Budé, hatte seit 1508 immer wieder betont, dass der Ruhm des Königs

21 François hatte sich zusammen mit Clément Marot als Herausgeber der Werke von François Villon betätigt; vgl. dazu Stephen Bamforth, „Clément Marot, François I ${ }^{\mathrm{er}}$ et les muses“, in: Gérard Defaux/Michel Simonin (Hrsg.), Clément Marot „Prince des poëtes françois“1496-1996. Actes du Colloque international de Cahors en Quercy 21-25 mai 1996 (Colloques, congrès et conférences sur la Renaissance. 7), Paris/Genève, Droz, 1997, S. 225-235, bes. S. 229. Darüber hinaus tritt François auch als Verfasser eigener Dichtungen in Erscheinung. Vgl. auch das Lob des Herrschers als „excellent Poëte“ in Marots Epistel Le Valet de Marot contre Sagon. Frippelines, secretaire de Clément Marot à Françoys Sagon, secretaire de l'Abbé de Sainct Evroul (in: Marot, Euvres poètiques complètes, Bd. 2, S. 144 [Nr. XXIV]). Zu den Dichtungen des Königs vgl. François I ${ }^{\mathrm{er}}$, Euvres poétiques, hrsg. von June-Ellen Kane (Textes de la Renaissance. 56), Paris, Garnier, 1984. Vgl. auch Bamforth, „Clément Marot”, S. 226-231, sowie Timothy Hampton, „Vergers des Lettres: L'allégorie politique et morale dans L'Enfer“, in: Defaux/Simonin (Hrsg.), Clément Marot „Prince des poëtes françois“ 1496-1996, S. 237-248. Zu den zeitgenössischen Vorstellungen vom Bildungsprogramm des „royaulme pacifique“ sowie dem berühmten Brief Gargantuas an Pantagruel vgl. François Rabelais, Pantagruel (1532), in: F. R., Euvres complètes, 2 Bde., hrsg. v. Pierre Jourda (Classiques Garnier), Paris, Garnier, 1962, Bd. 1, S. 211-387, bes. S. 257 (Kap. 8).

22 Vgl. dazu Michèle Clément, „Marot politique dans L’Adolescence clémentine et dans La Suite“, in: Gérard Defaux (Hrsg.), La Génération Marot. Poètes français et néo-latins (1515-1550). Actes du Colloque international de Baltimore 5-7 décembre 1996 (Colloques, congrès et conférences sur la Renaissance. 11), Paris/Genève, Droz, 1997, S. 155-167, bes. S. 163. 
durch die Liebe zur ,sapientia' begründet wird ${ }^{23}$. Budé beruft sich zum Beweis auf die Weisheitsbücher des Alten Testaments, insbesondere auf den Liber proverbiorum Salomonis 25, 2, wo es heißt, Gottes Ehre sei es, eine Sache zu verbergen, und der Könige Ehre, sie zu ergründen: „Gloria Dei celare verbum et gloria regum investigare sermonem“24. Für Budé hat dieser Auftrag zwei grundlegende Konsequenzen: Zunächst verleiht er dem König eine sakrale Stellung. Der als absolut gesehene Herrscher (,[...] les Roys [...] ne sont subiects aux lois [...]“25) steht auf besondere Art und Weise in einem Filiationsverhältnis zu Gott, der sein natürlicher und geistiger Vater ist: „[...] telz hommes sont filz naturel \& adoptifz de DIEV [...]“26 Die aus dem Mittelalter überlieferte Vorstellung vom ,princeps imago Dei“ bekommt bei Budé messianische Züge: Nicht nur Christus habe in seinem Evangelium in Gleichnissen gesprochen („[...] nostre SEIGNEVR a parlé en son Evangile par paraboles \& comparaisons figurées [...]“27), um die reine Wahrheit („la pure verité, qui est la lumiere“28) an die richtigen Adressaten, die Gläubigen, zu bringen. Auch die Worte des Königs seien orakelhaft („,...] les parolles d'vn Prince sont comme oracles [... ]“29). Sie verleihen dem Hof einen heiligen Charakter: „[...] la Cour d’vn Roy, est [...] come le sainctuaire de Maiesté [...]“30

Aus dem Spruch Salomons ergibt sich jedoch noch eine andere, für Budé weitaus wichtigere Konsequenz: Der Auftrag, Gottes dunkle Worte zu erforschen ${ }^{31}$, erfordert eine anstrengende gedankliche Arbeit sowie das nötige Wissen: „[...] pur et infaillible science, qui est Sapience, si peult acquerir [...] par grand labeur, [...] ou par sçauoir [...]“32 Über diese Qualitäten verfügen vor allem die Gelehrten, die das seit der Antike überlieferte Wissen im Geist der Evangelien aufgearbeitet haben. Der wahre Ruhm des Königs besteht darin, die Bücher dieser Gelehrten zu ehren („[...] c'est gloire royale, que honorer les liures de ceulx, qui ont le sçauoir

23 Budé, De l'Institution du Prince. Liure contenant plusieurs Histoires, Enseignements, \& saiges Dicts des Anciens tant Grecs que Latins, Paris 1547; Nachdruck: Farnborough. Gregg, 1966, S. 86.

24 S. 85.

25 S. 20.

26 S. 84.

27 S. 85.

28 S. 86.

29 S. 83.

30 Ebd.

31 Vgl. dazu Peter von Moos, „Was galt im Mittelalter als das Literarische an der Literatur? Eine theologisch-rhetorische Antwort im 12. Jahrhundert“, in: Joachim Heinzle (Hrsg.), Literarische Interessenbildung im Mittelalter. DFG-Symposion 1991 (Germanistische Symposion-Beiträge. 14), Stuttgart/Weimar, Metzler, 1993, S. 431-451.

32 S. $85 \mathrm{f}$. 
de composer \& escrire saigement [... ““33). Zu seiner Ehre gereicht es, wenn er sich ihrer als Berater bedient: „[... ] l'honneur du Roy \& des Princes est, de porter honneur aux choses honorables, en se servant \& aydant des hommes sçauants, \& en vsant du conseil de ceulx, qui ont acquis Science \& Prudence par grand labeur [...]“34 Aus dem Spruch Salomons erfolgt somit für Budé eine Verpflichtung des Königs zum Mäzenatentum. Entscheidend ist, inwieweit sich die Könige von ihren Beratern lenken lassen („,comment ilz se laissent gouuerner“35).

Nun sind es genau diese Anschauungsmuster, auf die die Epître au Roy abstellt. Marot pervertiert die Anschauung Budés, der Herrscher sowie die mit ihm verbundenen Theologen und Wissenschaftler seien für die Erforschung der dunklen Sprache Gottes zuständig. Wenn dies so ist, kann er sich ebenfalls einer dunklen, orakelhaften Sprache bedienen, da der König ja - laut Budé - in der Lage ist, diese zu enträtseln. Die Legitimation für sein dunkles, verhülltes Sprechen leitet er somit aus den Lehren der zeitgenössischen Theologen ab. Auch er betont die Sakralität des Königtums: Der Herrscher ist, so suggeriert es die Stelle vom Ausschluss des Schäfchens Clément aus der königlichen Herde, wie König David Hirte seiner Anvertrauten, ,pastor populi‘, wie es in den Prinzenerziehungstraktaten heißt ${ }^{36}$. Der gesamte Brief stellt das Prinzip der Filiation, der Übergabe des Erbes vom Vater an den Sohn in den Mittelpunkt und hält dem König somit vor, dass er vor allem Gottes Erbe verwalte: Der ewige Ruhm des Herrschers, so lassen sich die Verse $31 \mathrm{f}$. lesen, wird allein durch diese Filiation begründet:

Je quiers sans plus, Roy, de los eternel,

Estre heritier du seul bien Paternel.

Entsprechend heißt es auch bei Marot - in analoger Verwendung der Formulierung Budés -, das Königswort sei prophetisches Gotteswort: „[...] vostre dire est ung divin Oracle [...]“

Im Mittelpunkt der Epître au Roy steht jedoch wie in Budés De l'institution du Prince die Einforderung des Mäzenatentums. Hier stellt sich der Dichter neben den Theologen und Wissenschaftler. François I. wird als moderner David, als Sänger angesprochen. Dies erlaubt es dem Autor, sich dem Herrscher auf gleicher

33 S. 87.

34 S. $87 \mathrm{f}$.

35 S. 82.

36 Vgl. Budé, De l'Institution du Prince, S. 30. Vgl. dazu auch Pierre Mesnard, L'Essor de la philosophie politique au XVI ${ }^{e}$ siècle, Paris, Vrin, 1951, S. 120 f. Zu François als Sängerkönig David vgl. die Widmungsepistel der Psalmenübersetzungen von Clément Marot, Euvres poétiques complètes,

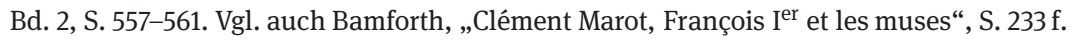


Ebene, sozusagen von Dichter zu Dichter, zu nähern und mit ihm eine Art Konversation unter Humanisten und Freunden zu führen (V. 54-56):

Tu en pourras dicter Lay, ou Epistre,

Et puis la faire à tes Amis tenir,

Pour en l'Amour d'iceulx t'entretenir.

In scherzhafter Anspielung auf die gelasianische Lehre von den zwei Schwertern, die im Protestantismus als Lehre von den zwei Reichen, dem geistigen und dem weltlichen Reich, eine besondere Schärfe gewinnt, sind die Rollen im Gespräch zwischen Herrscher und Dichter für Clément klar verteilt. Ist der König hauptsächlich für die zeitlich-weltlichen Wohltaten zuständig (,[...] vos Bienfaictz étoient son Temporel [...]“ [V. 98]), so wähnt sich der Dichter als Erbe des spirituellen Wissens des Vaters. Es handelt sich - ganz im Sinne der wiederum für die reformatorische Bewegung zentralen Weisheitsbücher sowie der Briefe des Paulus an die Korinther und die Galater - um ein reines, geradezu evangelisches Wissen, mit dem der Dichter anders als z. B. die an der Universität ausgebildeten Priester und ,maîtres ès arts', die Kaufleute, die Advokaten und die Ärzte, keinerlei Schaden anrichten könne (die Verse 46-52):

\footnotetext{
C’est ung sçavoir tant pur, \& innocent,

Qu'on n'en sçauroit à creature nuire.

Par Preschemens, le Peuple on peult seduire:

Par Marchander, tromper on le peult bien:

Par Plaiderie, on peult menger son bien:

Par Medecine, on peult l'homme tuer:

Mais ton bel Art ne peult telz coups ruer [...]
}

Clément Marot sieht sich als Mahner im Sinne der Bücher zur Prinzenerziehung, der dem hauptsächlich in weltlichen Dingen befangenen König die spirituellen Grundlagen seiner Macht aufzeigt. Dabei schiebt er durch seine orakelhafte, indirekte Sprache dem König die grundlegenden Anschauungen des neuen Glaubens unter: Grundsätzlich sucht sich der Dichter eine grundlegende innere Unabhängigkeit zu bewahren, wenn er ganz unverhohlen das zentrale Credo der reformatorischen Bewegung ,Soli Deo Honor et Gloria“ - nach Martin Luther ,Allein Gott in der Höh sei Ehr ${ }^{37}$ - formuliert. In V. 62-65 heißt es nämlich, an den Beginn eines jeden literarischen Werks gehöre der Name des Allmächtigen, und erst dann

37 Zur Bedeutung dieses Credos selbst für die Sprachwissenschaft der Zeit vgl. Franz Josef Hausmann, Louis Meigret. Humaniste et linguiste (Lingua et Traditio. 6), Tübingen, Narr, 1980, bes. S. $63 \mathrm{f}$. 
könne sich der Dichter dem weltlichen Ruhm irgend eines Königs oder Fürsten widmen:

\section{[...] en la Fueille premiere}

Doibs invocquer le nom du tout puissant:

Puis descriras le bruit resplendissant

De quelcque Roy, ou Prince [...]

Der höfische Dichter ist nach Clément Marot nicht länger Berichterstatter der Kriegstaten seines Herrn ${ }^{38}$, sondern gelehrter Diskussionspartner des Herrschers ${ }^{39}$. Der Dichter der Epître au Roy ist - mit Thomas More gesprochen - „The king's good servant, but God's first“"40. Dieses Programm wird dem König auf gut gelaunte, indirekte Art im Stil einer Plauderei mitgeteilt.

\subsection{Die indirekte Ansprache an den Herrscher: der Bittbrief als politische Satire}

Im Laufe der auf die Epître au Roy von 1527 folgenden Jahre, in denen Clément Marot Briefe an François Ier verfasst, geht es zunehmend darum, den Herrscher für die Sache der Reformation zu gewinnen. Nicht nur die religiösen und politischen Positionen des Autors werden dabei immer deutlicher. Auch die ironischen Pointen des ,élégant badinage‘, über die der Dichter seine Anschauungen transportiert, gewinnen an Schärfe. Von daher ist es unverständlich, warum der Literatur zu Marot der Hintergrund der Epître au Roy von 1532, die gemeinhin als Epître au Roy, pour avoir été dérobé bekannt ist und als Meisterwerk des style marotique gilt ${ }^{41}$, bislang völlig verborgen geblieben ist. Auch diese Epistel ist eine ,lettre de requête', deren Aufbau alleine zeigt, dass Marot mit juristischen Eingaben bestens vertraut war.

38 Vgl. dazu Clément, „Marot politique dans L’Adolescence clémentine et dans La Suite“, S. 157, die von einem „refus de la ,Muse publicitaire““ spricht.

39 Vgl. Olivia Rosenthal, „Clément Marot: Une poétique de la requête“, in: Clément Marot „Prince des poëtes françois“ 1496-1996, S. 283-299, hier: S. 297, die Marots Briefe als „épître familière“ und als „conversation entre amis“ sieht.

40 Vgl. dazu Clément, „Marot politique dans L’Adolescence clémentine et dans La Suite“, S. 166. 41 Vgl. dazu Joseph Vianey, Les Epîtres de Marot, Paris, Nizet 1962, S. 72, sowie Kenneth LloydJames, „Une ,superchérie‘ de Marot“, Studi francesi Jg 22/1978, S. 369-373, bes. S. 372. 
On dit bien vray, la maulvaise Fortune

Ne vient jamais, qu'elle n'en apporte une, Ou deux, ou trois avecques elle (Sire). Vostre cueur noble en sçauroit bien que dire: 5 Et moy chetif, qui ne suis Roy, ne rien

L’ay esprouvé. Et vous compteray bien,

Si vous voulez, comment vint la besongne. J'avois ung jour un Valet de Gascongne, Gourmant, Yvroigne, \& asseuré Menteur, 10 Pipeur, Larron, Jureur, Blasphemateur, Sentant la Hart de cent pas à la ronde, Au demeurant le meilleur filz du Monde, Prisé, loué, fort estimé des filles Par les Bourdeaux, \& beau Joueur de Quilles. 15 Ce venerable Hillot fut adverty De quelcque argent, que m'aviez departy, Et que ma Bourse avoit grosse apostume: Si se leva plus tost que de coustume, Et me va prendre en tapinois icelle:

20 Puis la vous mist tresbien soubz son Esselle, Argent \& tout (cela se doibt entendre), Et ne croy point, que ce fust pour la rendre, Car oncques puis n'en ay ouy parler. Brief, le Villain ne s'en voulut aller 25 Pour si petit: mais encor il me happe Saye, \& Bonnet, Chausses, Pourpoinct, \& Cappe : De mes Habitz (en effet) il pilla Tous les plus beaulx: et puis s'en habilla Si justement, qu'à le veoir ainsi estre, 30 Vous l'eussiez prins (en pleinjour)pour son Maistre.

Finablement, de ma Chambre il s'en va Droit à l'estable, où deux Chevaulx trouva : Laisse le pire, \& sur le meilleur monte, Picque, \& s'en va. Pour abreger le compte, 35 Soiez certain, qu'au partir dudict lieu N'oublya rien, fors à me dire Adieu.

Ainsi s'en va chastoilleux de la gorge Ledict Valet, monté comme ung sainct George: et vous laissa Monsieur dormir son saoul: 40 Qui au resveil n'eust sceu finer d'un soul. Ce Monsieur là (Sire) c'estoit moy mesme: Qui sans mentir fuz au Matin bien blesme, Quand je me vy sans honneste vesture,
Zurecht heißt es, dass ein Unglück selten alleine Kommt (Herr):

Euer nobles Herz weiß wohl davon zu berichten. 5 Und ich Armseliger, der ich weder König bin, Noch Sonst etwas, Habe es am eigenen Leib erfahren. Ich will Euch wohl, Wenn Ihr wollt, erzählen, wie die Angelegenheit (Not ?) entstanden ist. Ich hatte einst einen Diener aus der Gaskogne, Schlemmer, Trunkenbold und dreister Lügner, 10 Fallensteller, Dieb, Vielschwörer, Gotteslästerer, der den Strick hundert Meter im Umkreis roch, Übrigens der beste Junge auf der Welt, Geachtet, gelobt, sehr geschätzt von den Mädchen, Von den Flausenmachern, und guter Kegelspieler. 15 Dieser ehrwürdige Junge wurde einer Geldsumme gewahr, die Ihr mir zugeteilt hattet, und dass meine Börse eine große Geschwulst hatte: So erhob er sich früher als gewöhnlich, und nimmt mir diese heimlich ab:

20 Dann tat er sie wohl unter seinen Sattel, Geld und Alles (das versteht sich von selbst), Und ich glaube nicht, um es zurückzugeben, Denn niemals habe ich seitdem wieder davon gehört. Kurzum, der Übeltäter wollte nicht wegen so $\mathbf{2 5}$ Wenig gehen: Darüberhinaus schnappt er Mir Koller und Mütze, Beinkleider, Wams und Umhang weg. Von meinen Kleidern stahl er (in der Tat) Die schönsten: Und dann zog er sich so korrekt An, dass Ihr ihn, wenn Ihr ihn so gesehen hättet, 30 (am hellichten Tag) für seinen Herrn gehalten hättet.

Schließlich geht er von meinem Zimmer Direkt in den Stall, wo er zwei Pferde fand: Er lässt das schlechtere stehen und besteigt das Beste, Stiehlt es und verschwindet. Um den Bericht abzukürzen, 35 Seid versichert, dass er beim Abschied von besagtem Ort Nichts vergaß, außer mir 'Auf Wiedersehen' zu sagen. So geht besagter Diener dahin, kitzelig am Hals, Aufgesessen wie ein Heiliger Georg Und lässt seinen Herrn seinen Rausch ausschlafen, 40 Der beim Erwachen ohne einen Pfennig dastand. Dieser Herr (Herr) war ich selbst: Der, ohne zu lügen, am Morgen recht blaß war, Als ich mich ohne ehrenhafte Bekleidung sah 
et fort fasché de perdre ma monture:

45 Mais de l'argent, que vous m'aviez donné, Je ne fuz point de le perdre estonné, Car vostre argent (de tresbonnaire Prince) Sans point de faulte est subject à la pince. Bien tost apres ceste fortune là,

50 Une aultre pire encores se mesla De m'assaillir, \& chascun jour me assault, Me menassant de me donner le sault, Et de ce sault m'envoyer à l'envers, Rymer soubz terre, \& y faire des Vers. 55 C'est une lourde, \& longue maladie De troys bons moys, qui m'a toute eslourdie La pauvre teste, $\&$ ne veult terminer, Ains me contrainct d'apprendre à cheminer. Tant affoibly m'a d'estrange maniere, 60 Et si m'a faict la cuisse heronniere, L'estomac sec, le Ventre plat, \& et vague: Quand tout est dit, aussi maulvaise bague (Ou peu s'en fault) que femme de Paris, Saulve l'honneur d'elles, \& leurs Maris. 65 Que diray plus? Au miserable corps (Dont je vous parle) il n'est demouré fors Le pauvre esprit, qui lamente, \& souspire, Et en pleurant tasche à vous faire rire. Et pour aultant (Sire) que suis à vous, 70 De troys jours l'ung viennent taster mon poulx

Messieurs Braillon, le Coq, Akaquia,

Pour me garder d’aller jusque à quia.

Tout consulté ont remis au Printemps Ma guerison: mais à ce que j'entends,

$75 \mathrm{Si}$ je ne puis au Printemps arriver, Je suis taillé de mourir en Yver, Et en danger (si en Yver je meurs) De ne veoir pas les premiers Raisins meurs. Voilà comment depuis neuf moys en çà $\mathbf{8 0}$ Je suis traicté. Or ce que me laissa Mon Larronneau (long temps a) l'ay vendu, Et en Sirops, \& Julez despendu:

Ce neantmoins ce que je vous en mande, N'est pour vous faire ou requeste, ou demande:

$\mathbf{8 5}$ Je ne veulx point tant de gens ressembler, Qui n'ont soucy aultre que d'assembler.
Und sehr böse war, mein Gespann verloren zu haben: 45 Ich war allerdings nicht erstaunt, das Geld, das Ihr mir gegeben hattet, zu verlieren, Denn Euer Geld (von einem gütigen Herrscher) Ist ganz gewiss dem Diebstahl unterworfen. Bald nach diesem Unglück

50 Mischte sich ein anderes ein, mich zu Attackieren, und es greift mich jeden Tag an, Indem es mich bedroht, mir den letzten Sprung zu geben, Um mich mit diesem Sprung auf den Kopf zu stellen, Unter der Erde zu reimen und dort Verse zu machen. 55 Es handelt sich um eine schwere und langwierige Krankheit von drei Monaten, die mir Ganz den armen Kopf beschwert hat und nicht enden will, Mich gleichwohl zwingt, gehen zu lernen.

Sie hat mich auf sonderbare Weise derart

60 Geschwächt und mir Beine wie ein Reiher, einen trockenen Magen, einen flachen und leeren Bauch eingebracht: Kurzum, wie ein falscher Edelstein [wie eine Prostituierte], Oder (beinahe), wie eine Frau aus Paris;

[meine Krankheit] rettet ihre Ehre und die ihrer Ehemänner. 65 Was soll ich noch sagen? Dem erbarmungswürdigen Körper, (von dem ich Euch erzähle), ist nichts außer Einem armseligen Geist, der klagt und seufzt, geblieben, Und beim Weinen versucht, Euch zum Lachen zu bringen. Und soviel ich Der Eurige bin, 70 Sind seit drei Tagen die Herren Braillon, Le Coq und Akaquia gekommen, meinen Puls zu fühlen, Um mich davor zu bewahren, bis ans Ende zu gehen.

Als sie ihre Konsultationen abgeschlossen hatten, haben sie Meine Heilung auf das Frühjahr verschoben: Doch, wenn ich, so

75 Wie ich es verstanden habe, nicht bis zum Frühjahr komme, Bin ich dazu bestimmt, im Winter zu sterben Und der Gefahr ausgesetzt, (wenn ich im Winter sterbe), Die ersten reifen Trauben nicht mehr zu sehen.

Seht wie ich seit neun Monaten in dieser Angelegenheit $\mathbf{8 0}$ Behandelt werde. Nun, das, was mir mein Spitzbube Gelassen hat, habe ich (schon vor langer Zeit) verkauft Und für Sirop und Heilsäfte ausgegeben.

Nichtsdestotrotz geht es bei dem, worum ich Euch bitte, Nicht darum, Euch ein Ersuchen oder eine Forderung vorzutragen.

85 Ich möchte nicht den vielen Leuten ähneln, Die keine andere Sorge haben, als aufzuhäufen. 
Tant qu'ilz vivront, ilz demanderont eulx, Mais je commence à devenir honteux, Et ne veulx plus à vos dons m'arrester. 90 Je ne dy pas, si voulez rien prester, Que ne le preigne. II n'est point de Presteur (S'il veult prester) qui ne fasse ung Debteur. Et sçavez vous (Sire) comment je paye? Nul ne le sçait, si premier ne l'essaye. 95 Vous me debvrez (si je puis) de retour : Et vous feray encores ung bon tour, A celle fin qu'il ny ayt faulte nulle, Je vous feray une belle Cedulle, $A$ vous payer (sans usure il s'entend) 100 Quand on verra tout le Monde content: $\mathrm{Ou}$ (si voulez) à payer ce sera, Quand vostre Loz, \& Renom cessera. Et si sentez, que soy foible de reins Pour vous payer, les Deux Princes Lorrains 105 Me plegeront. Je les pense si fermes, Qu'ilz ne fauldront pour moy à l'ung des termes.

Je sçay assez, que vous n'avez pas peur Que je m'en fuie, ou que je soys trompeur: Mais il faict bon asseurer ce, qu'on preste. 110 Brief, vostre paye (ainsi que je l'arreste) Est aussi sceure, advenant mon trespas, Comme advenant, que je ne meure pas. Advisez donc, si vous avez desir De rien prester, vous me ferez plaisir : 115 Car puis ung peu, j'ay basty à Clement, Là où j'ay faict ung grand desboursement: Et à Marot, qui est ung peu plus loing : Tout tumbera, qui n'en aura le soing. Voilà le poinct principal de ma Lettre. 120 Vous sçavez tout, il n'y fault plus rien mettre:

Rien mettre, las! Certes, \& si feray, En ce faisant, mon stile j'enfleray, Disant, ô Roy amoureux des neuf Muses, Roy, en qui sont leurs sciences infuses, 125 Roy, plus que Mars, d'honneur environné, Roy, le plus Roy, qui fut oncq couronné, Dieu tout puissant te doint (pour t'estrener) Les quatre coings du Monde gouverner, Tant pour le bien de la ronde Machine, 130 Que pour aultant, que sur tous en es digne.
Solange sie leben, werden sie fordern

Aber ich beginne, mich zu schämen

Und will nicht länger an Euren Gaben haften.

90 Ich sage nicht, wenn Ihr etwas leihen wollt, Dass ich es nicht nähme. Es gibt keinen Verleiher (Wenn er leihen will), der sich nicht einen Schuldner macht. Und wißt Ihr (Herr) wie ich bezahle?

Niemand weiß es, wenn er es nicht als erster ausprobiert. 95 Ich schulde Euch, (wenn ich kann), eine Gegengabe. Und ich werde Euch noch einen Dienst erweisen, Damit keine Verschuldung bestehen bleibt.

Ich werde Euch einen schönen Schuldschein ausstellen, Um Euch zu bezahlen (ohne Zins versteht sich), 100 Wenn man die ganze Welt zufrieden sieht: Oder, (wenn Ihr wollt), wird diese Schuld zu bezahlen sein, Wenn Euer Ruhm und Ruf nachläßt.

Und wenn Ihr Anzeichen dafür habt, daß ich finanziell Schwach auf der Brust bin, werden die beiden Fürsten aus 105 Lothringen für mich bürgen. Ich halte sie für so standhaft, Dass sie für mich an einem Fälligkeitstag nicht wegbleiben werden.

Ich bin sicher, daß Ihr keine Angst habt, Dass ich fliehe, oder daß ich ein Betrüger bin. Aber man muss das, was man leiht, gut absichern. 110 Kurzum, Euer Geld (sobald ich es fest in der Hand habe) Ist so sicher, wie mein Tod, [oder] wie mein Weiterleben. Gebt also acht, ob Ihr Lust habt, Etwas zu leihen, Ihr würdet mir einen Gefallen tun. 115 Denn ich habe ein bißchen in Clement gebaut, Dort wo ich eine große Ausgabe getätigt habe, Und in Marot, das ein bißchen weiter weg liegt: Alles wird einstürzen, das nicht unterhalten wird. Dies der Hauptpunkt meines Briefes.

$120 \mathrm{lhr}$ wißt alles, man muß nichts mehr hinzufügen.

Nichts hinzufügen, ach! Sicher, und ich mache es so, Indem ich es tue, blähe ich meinen Stil auf, Indem ich sage, oh König, Liebhaber der neun Musen, König, in den ihr Wissen eingegossen ist, 125 König, mehr als Mars von Ehre umgeben, König, der größte König, der jemals gekrönt wurde, Der allmächtige Gott möge Dir, (um Dich zu beschenken), Die Regierung über die vier Enden der Welt geben, So sehr wegen des Wohls der runden Maschine, 130 Als auch deswegen, weil Du mehr als alle dessen würdig bist. 
Mehr noch als die Epistel Au Roy von 1527 nähert sich dieser Brief dem König im Stil einer scheinbar belanglosen Plauderei. Die Epistel enthält ein exordium (V. 1-7), in dem der Dichter dem König erklärt, mehrere Schicksalsschläge erlitten zu haben. Die propositio beginnt mit der Erzählung des ersten Falls (V. 8-48): Clément ist, als er eines morgens seinen Rausch ausschlief, von seinem gaskognischen Diener um Pferd, Bekleidung sowie eine Geldsumme gebracht worden, die ihm der König kurz zuvor angewiesen hatte. In der narratio des zweiten Schicksalsschlages der Verse 49-78 berichtet der Dichter von einer schweren Erkrankung, die ihn nach dem Diebstahl seines Hab und Guts heimgesucht und finanziell endgültig ruiniert habe. Die argumentatio der Verse 79-119 fordert alsdann den König auf, dem Dichter das dringend benötigte Geld zu leihen. Der Brief schließt mit der peroratio der Verse 119-130, in denen Clément den König scheinbar preist.

Die in Frankreich bis heute beliebte biographische Lesart literarischer Texte hat im Fall dieser Epître au Roy Erstaunliches zutage gebracht. Nicht allein, dass der Autor offenkundig an der 1531 im Lande grassierenden Pest erkrankt war ${ }^{43}$. Auch die Begründung des Dichters für die Geldforderung in V. 115 und V. 117, er brauche finanzielle Unterstützung für seine Güter in ,Clément' sowie in ,Marot‘, scheint auf Tatsachen zu beruhen, da es sich um zwei Ortschaften in der Nähe der Geburtsstadt des Autors Cahors en Quercy handelt, in denen Clément Marot in der Tat Häuser besaß ${ }^{44}$. Den König scheinen - so das Fazit dieser Interpretationen - die in ein burleskes Gewand gekleideten realistischen Angaben offenkundig überzeugt zu haben, da er dem Dichter wenige Wochen nach der Absendung der Epistel nachweislich eine größere Geldsumme zur Verfügung gestellt hat.

Gegen solch biographische Lesarten der Epistel spricht allerdings, dass es sich beim Genus der ,lettre de requête‘ um eine seit dem späten Mittelalter verbreitete Gattung handelt, deren Anschauungsmuster geradezu topischen Charakter haben. Die Vorstellung vom aufgrund einer Krankheit mittellosen Dichter findet sich bereits in der berühmten, nach 1261 abgefaßten Complainte Rutebeuf, einem Bittschreiben an den Grafen von Poitiers ${ }^{45}$. In der Lyrik von Eustache Deschamps aus der zweiten Hälfte des 14. Jahrhunderts, die besonders viele Bittgedichte enthält, gibt es gleich mehrere Balladen über die Diener, die ihren Herrn

42 Clément Marot, Au Roy, aus: La suite de l'adolescence clémentine, S. 320-323 (Nr. XVIII).

43 Vgl. dazu Jean-Luc Dejean, Clément Marot, Paris, Fayard, 1990, S. 194.

44 Vgl. dazu Claude-Albert Mayer, Clément Marot, Paris, Seghers, 1972, S. 183, mit. Anm. 58. 45 „Car j’ai geü / Trois mois que nului n’ai veü.“ (Abgedruckt in: Albert Pauphilet, Poètes et romanciers du Moyen Age [Bibliothèque de la Pléiade. 52], Paris, Gallimard, 1952, S. 931, V. 94 f.). Dort auch die sprichwörtliche Redensart: „Li mal ne sevent seul venir [...]“(V. 107), derer sich auch Marot zu Beginn der Epître au Roy bedient. 
Geld und Pferde stehlen ${ }^{46}$. Besonders einschlägig ist jedoch François Villons Requête à Monseigneur de Bourbon aus der Mitte des 15. Jahrhunderts, der Marot nicht nur die Reimwörter „,assault“ und ,sault“ der Verse 51 und 52 entnimmt, sondern auch die Vorstellung, der König möge dem Dichter Geld borgen, aber selbstverständlich ohne Zins (V. 98-99):

Je vous feray une belle Cedulle,

A vous payer (sans usure il s'entend) $[\ldots]^{47}$

Bei allen Wahrheitsbekundungen, die die Epître au Roy, pour avoir été dérobé von Beginn an durchziehen, ist die Wahrheit doch nur ein ,effet de réel', den Marot zeitweilig produziert ${ }^{48}$. Auf der einen Seite erzeugt er eine solche Wirklichkeitsillusion z. B. dadurch, dass der Erzähler in den Versen 15-39 den Diebstahl durch den Diener in Gestalt eines Augenzeugenberichts übermittelt. Auf der anderen Seite wird diese Illusion immer wieder durch die Klischeehaftigkeit des Berichteten zerstört, wenn es z. B. ganz unkonkret heißt: „J'avais ung jour un Valet de Gascongne [...]“ (V. 8), wobei die Herkunft des Dieners von vornherein nichts Gutes erwarten lässt, da man den Bewohnern der Gaskogne eine sprichwörtliche Verschlagenheit nachsagt ${ }^{49}$. Durch dieses Spiel mit der Illusionierung und der Desillusionierung des Lesers entsteht ein Verfremdungseffekt, der zeigt, dass Marot auch mit dieser Epistel keine vordergründige ,lettre de requête'verfasst, sondern erneut spielerisch auf indirekte Weise auf etwas ganz anderes aufmerksam machen will.

Interessant ist die auffällige peroratio der Epistel ab V. 119, die auf den ersten Blick an Impertinenz kaum zu überbieten ist. Marot hat sein Anliegen, die Bitte um Geld, dem König vorgetragen und schließt mit den Worten:

Voilà le poinct principal de ma Lettre.

Vous sçavez tout, il n'y fault plus rien mettre:

46 Vgl. z. B. die Ballade DCCCLXXXVII in Eustache Deschamps, Euvres complètes de Eustache Deschamps, hrsg. vom Marquis de Queux de Saint-Hilaire (Société des anciens textes français), Paris 1877, Bd. 5, S. 72 f. Vgl. auch Christine Scollen-Jimack, „Marot and Deschamps: The Rhetoric of Misfortune“, French Studies Bd. 42/1988, S. 21-32, bes. S. 26-29.

47 In: François Villon, Euvres, 3 Bde., hrsg. von Louis Thusane, Paris, Picard, 1923, Bd. 1, S. 278 (V. 36 und V. 39). Vgl. auch S. 276 f. (V. 6 und V. 9).

48 Vgl. dazu Annwyl Williams, Clément Marot: Figure, Text and Intertext (Studies in Renaissance Literature. 8), Lewiston/Queenston/Lampeter, The Edwin Mellen Press, 1990, S. 59.

49 Marots Epistel ruft unter anderem ein zeitgenössisches Gedicht auf, dessen Verfasser sich über diese Beleidigung der Gaskogner beschwert (vgl. dazu Philipp August Becker, Clément Marot. Sein Leben und seine Dichtung [Sächsische Forschungsinstitute in Leipzig. Forschungsinstitut für neuere Philologie IV. Romanistische Abteilung. 1], München, Kellerer, 1926, S. 269). 
Die folgende Aposiopese macht deutlich, dass dem Brief offenbar doch noch etwas fehlt, nämlich die Huldigung des Herrschers, die Clément im Verlauf der Eingabe angeblich vergessen hatte und die er nun unter Aufbietung aller rhetorischen Mittel nachholt:

\footnotetext{
Rien mettre, las! Certes, \& si feray,

En ce faisant, mon stile j'enfleray,

Disant, ô Roy amoureux des neuf Muses,

Roy, en qui sont leurs sciences infuses,

Roy, plus que Mars, d'honneur environné,

Roy, le plus Roy, qui fut oncq couronné,

Dieu tout puissant te doint (pour t'estrener)

Les quatre coings du Monde gouverner,

Tant pour le bien de la ronde Machine,

Que pour aultant, que sur tous en es digne.
}

Der Hinweis in V. 122 auf den Stil dieser peroratio, der durch die rhetorischen Verfahren geradezu aufgebläht werde: „,...] mon stile j'enfleray [...]“, zeigt, dass es Marot mit dieser Art der Panegyrik nicht allzu ernst ist. Dass er insbesondere den von der klassischen Mythologie durchtränkten Stil der Rhétoriqueurs parodiert ${ }^{50}$, zu denen auch sein Vater gehörte, ist an der satirischen Spitze in V. 125 erkennbar, in der François Ier mehr Ehre als dem Kriegsgott Mars zugeschrieben wird.

Bekanntlich ist François Ier in seinen Bemühungen um die universelle Herrschaft durch die Wahl des Habsburgers Karls des Fünften zum Kaiser im Jahre 1519 gescheitert. 1525 wird er in der Schlacht von Pavia gefangengenommen und von Karl für längere Zeit in Madrid festgesetzt. Diese Gefangennahme löst in Frankreich ein regelrechtes Trauma aus, zumal die Sorbonne und die Parlements die Abwesenheit des Königs zur aktiven Verfolgung der reformatorischen Bewegungen im Lande nutzen. Wenn es daher in V. 125 der Epître au Roy wie schon in der Versepistel von 1527 in satirischer Anspielung auf diesen Hintergrund heißt, der König habe mehr Ehre als der Kriegsgott und wenn es bereits zu Beginn der Epistel in V. 4 geheißen hatte, auch François wisse von Schicksalsschlägen zu berichten: „Vostre cueur noble en sçauroit bien que dire [...]", so wird deutlich, dass Clément auch hier jedwede Huldigung kriegerischer Taten verweigert und den diesem Sujet angemessenen pathetisch-hohen Stil parodiert.

Im Scherzhaft-Spielerischen dieser Stelle steckt jedoch bei genauerer Betrachtung wiederum eine ernsthafte Aussage. Die Feststellung, François Ier habe mehr Ruhm, als der Kriegsgott Mars, lässt sich auch so deuten, dass die Meriten des Königs auf einem anderen Feld liegen, auf dem nach Ansicht des Sprechers größerer

50 Dejean, Clément Marot, S. 201. 
Ruhm zu erwerben ist. Es handelt sich erneut um die Dichtkunst, die Musen, deren Wissen dem König eingegossen („leurs sciences infuses“ [V. 124]), d. h. per göttlichem Gnadenakt zuteil wurde. Aus dieser Gabe - so fährt die peroratio in V. 127 fort - leitet sich der Anspruch auf die Universalherrschaft des Königs ab, die das Gemeinwohl, das aus der aristotelischen Politik bekannte ,bonum commune‘, zum Ziel hat ${ }^{51}$ :

Dieu tout puissant te doint (pour t'estrener)

Les quatre coings du Monde gouverner,

Tant pour le bien de la ronde Machine [...]

Welcher Art dieses per Gnadenakt in den Herrscher eingegossene Wissen ist, wird nun erneut in Budés De l'Institution du Prince sowie in Erasmus Institutio principis christiani ausführlich erörtert. Für Budé gibt es eine weltliche Weisheit, die allein darauf ausgerichtet ist, Güter und Ruhm zu erwerben („Par sapience mondaine, on acquiert opulence de biens, \& renommée glorieuse, qui est le dernier but \& limite de cupidité [...]“52) Demgegenüber gibt es eine spirituelle Weisheit, die an den jenseitigen Dingen orientiert ist: „[... ] par spirituelle sapience, on a intelligence des biens eternelz, \& de la vie qui est à venir en l'aultre siecle [...]“53 Einige der modernen Monarchen - gemeint ist vor allem François Ier - seien im Gegensatz zu den Herrschern der Antike von dieser gottgegebenen Weisheit erfüllt: „[...] ceulx qui sont iourdhuy participans de la Philosophie inspirée, qui nous a esté transmise du ciel, \& communicquée par l'oracle de Sapience, \& de vérité [... ]“54 Diese Weisheit bedeutet für die Könige vor allem die Verpflichtung zur tätigen Nächstenliebe: „Charité \& amour enuers le peuple“ 55 .

Auch für Erasmus stehen Wissen und Weisheit des Königs ganz im Zeichen der Nächstenliebe. Erasmus benutzt die überlieferte Metapher vom König als Arzt, der die Krankheiten der Gesellschaft heilt ${ }^{56}$. Das beste Heilmittel ist die Freigebigkeit des Herrschers, der Erasmus ein eigenes Kapitel seiner Institutio widmet ${ }^{57}$. In der Freundlichkeit und Großzügigkeit, so heißt es dort, liegt der spezielle Ruhm des guten Fürsten: „[...] propria bonorum Principum laus [est] benignitas ac be-

51 Vgl. dazu Mesnard, L'Essor de la philosophie politique, S. 120.

52 Budé, De l'Institution du Prince, S. 32.

53 Ebd.

54 Ebd.

55 S. 30. Vgl. auch S. 32.

56 Erasmus von Rotterdam, Institutio principis christiani, in: Desiderii Erasmi Roterodami, Opera omnia, 10 Bde., hrsg. von Joannes Clericus, Leiden, 1703-1706; Nachdruck: Meisenheim am Glan, Olms, 1961-1962, Bd. 4, Sp. 559-612, Sp. 582 A (Kap. 2).

57 Sp. 595 f. (Kap. 5). 
neficentia [...]“58 Das Vorbild dieser Großzügigkeit ist die universelle Wohltätigkeit Gottes. Als Abbild des ewigen Herrschers ist der Fürst zum Geben ohne den Wunsch nach einer Gegengabe aufgefordert („Deus cum sit in omnia beneficus [...] Ita vere magni Principis est, ut aeterni Principis imaginem referentis, vel gratis bene mereri de omnibus, nullo vel emolumenti vel gloria respectu.").59

Nun behandelt Clément Marots Epître au Roy, pour avoir été dérobé genau dieses Problem. Seine Selbstdarstellung als ein von seinem Diener ausgeraubter Herr sowie als krank daniederliegender Patient greift zentrale Bilder der Beschreibung der öffentlichen Zustände aus der zeitgenössischen politischen Rhetorik auf. Im Fall des Diebstahls durch den Diener wird dieser Bezug von privatem Schicksal und öffentlicher politischer Situation explizit hergestellt, wenn Marot in V. 47-48 auf die ständigen Unregelmäßigkeiten bei der Verwaltung des königlichen Haushaltes hinweist:

Car vostre argent (de tresbonnaire Prince)

Sans point de faulte est subject à la pince.

Die Epistel mündet in einen Appell an die Freigebigkeit des Königs. Vor diesem Hintergrund mutet die scherzhaft-spielerische Bemerkung der Verse 93-94, ob der Dichter das geforderte Geld zurückzahlen könne, wisse niemand zu sagen, der es nicht ausprobiert habe, erneut als Impertinenz an:

Et sçavez vous (Sire) comment je paye?

Nul ne le sçait, si premier ne l'essaye.

Nun hat auch diese Bemerkung einen evangelischen Hintergrund, heißt es doch in der Bergpredigt nach Matthäus 5, 42, die von der Erfüllung des Gesetzes handelt: „[...] dem der dich bittet, gib, und wer bei dir borgen will, von dem wende dich nicht ab [...]“ (,„[...] qui petit a te da ei / et volenti mutuari a te ne avertaris [...]“), und noch deutlicher bei Lukas 6, 35: „[...] tut Gutes und leihet, / ohne etwas zurückzuerhalten [...]“ (,[...] benefacite et mutum date / nihil desperantes [...]“). Marot appelliert im Sinne dieser Erfüllung des Gesetzes an die Freigebigkeit des französischen Königs, die nach Budé und Erasmus die Grundeinstellung des modernen Fürsten sein muss. Um den König nicht ganz in Unsicherheit über die Rückzahlung der geliehenen Summe zu lassen, gibt Marot in den Versen 104 und 105 als Bürgen die Fürsten von Lothringen an. Auch diese Bemerkung hat eine scherzhafte und eine ernste Seite: Einerseits sind Claude und Jean de Lorrai-

58 Sp. 595 A.

59 Sp. 570 A (Kap. 1). 
ne ihrerseits beim König hoch verschuldet, ohne diese Schulden zurückzahlen zu können: „les Deux Princes Lorrain“ reimt sich auf „foible de reins“60. Andrerseits sind beide Fürsten wegen ihrer Mildtätigkeit berühmt, insbesondere der auch als Mäzen wirkende Kardinal Jean de Lorraine, bei dem sich ein in Rom von ihm reichlich beschenkter Blinder mit den Worten bedankt hat: „Si tu n'est pas le Christ, tu es le cardinal de Lorraine.“61

Clément Marots Epître au Roy, pour avoir été dérobé wie auch schon die Epistel $A u$ Roy von 1527 basieren somit ganz auf reformatorischen Anschauungen. Durch den Vortrag der bemitleidenswerten Existenz des Dichters ist sie gerade so aufgemacht, als wolle Marot dem Herrscher Gelegenheit geben, von der göttlichen Gabe der ,sapientia' und der aus ihr resultiernden ,caritas' Gebrauch zu machen ${ }^{62}$. Ihr Stil ist im Gegensatz zur rhetorischen peroratio einfach: Vor allem durch das sprichwörtliche Material, das Reden in Anakoluthen sowie durch zahlreiche, die Künstlichkeit des Versbaus zerstörende Enjambements erzeugt Marot den Eindruck spontanen Sprechens als Ausdruck innerer Aufrichtigkeit ${ }^{63}$. Die Äußerungen beider Briefe sind repräsentativ für die Dichtung Clément Marots, insbesondere die Dichtungen an François Ier. In einigen Episteln verlieren sie ihren allusiven Charakter und gewinnen geradezu programmatische Gestalt, insbesondere in der Déploration de Florimond Robertet von 1527, dem Brief an den König aus dem Exil in Ferrara von 1535 ( $A u$ Roy, du temps de son exil à Ferrare) und dem Widmungsbrief der Psalmenübersetzung an François Ier von 1541 (Au Treschrestien Roy de France, Françoys premier de ce Nom, Clemant Marot, Salut). Der ,élégant badinage' und die ,causerie facile' haben bereits in ihrer Entstehungsphase die Funktion einer subtilen Auseinandersetzung mit der Legitimation königlicher Autorität, in der der Autor die überlieferte Rolle vom Hofdichter als epischer Berichterstatter sowie als Panegyriker der Taten des Herrschers aufgibt und sich ei-

60 Vgl. die entsprechende Anmerkung von Defaux, Euvres poétiques complètes, Bd. 1, S. 725, Anm. 11.

$61 \mathrm{Zu}$ dieser bei Brantôme überlieferten Bemerkung vgl. Henry Guy, Histoire de la poésie française au XVI siècle, 2 Bde. (Bibliothèque littéraire de la Renaissance. Série 2.4 und 12), Paris, Champion, 1926, Bd. 2, S. 69.

62 Diese Auffassung vertritt Clément, „Marot politique“, S. 167: „Marot est [...] le ,despourveu“ qui peut aider le Roi à faire don de sa grâce [...]“ Vgl. auch Ullrich Langer, „L'Ethique de la louange chez Marot: La Ballade De paix, \& de victoire“, in: Defaux/Simonin (Hrsg.), Clément Marot „Prince des poëtes françois“, S. 268-S. 281, bes. S. 275.

$63 \mathrm{Zu}$ den Besonderheiten des Marotschen Stils vgl. insbesondere Gérard Defaux, „Rhétorique, silence et liberté dans l'œuvre de Marot. Essai d'explication d'un style“, Bibliothèque d’Humanisme et de Renaissance Bd. 46/1984, S. 299-322, sowie ders., „Clément Marot: une poétique du silence et de la liberté“, in: Jerry C. Nash, Pre-Pléiade Poetry (French Forum Monographies. 57), Lexington, Ken. 1985, S. 44-64. 
ne kritische Distanz zur Macht bewahrt. Die Epistel liefert in der Form indirekten Sprechens angelehnt an die mündliche Konversation eine profunde Kritik der $\mathrm{Zu}$ stände im Reich des Königs. Die spielerische Sprache hält die ,bienséances‘ ein, die sich insbesondere wegen ihres Adressaten gebieten. Zugleich eröffnet das indirekte Sprechen Marot auch jene Freiräume, seine Distanz zur königlichen Politik zum Ausdruck zu bringen. Ganz offenbar hat François Ier diese Angriffe aufgrund ihrer ästhetischen Perfektion goutiert und Clément Marot letztlich nicht nur weitgehend vor Verfolgungen in Schutz genommen, sondern ihn auch noch mit $\mathrm{Zu}$ wendungen ausgestattet. 